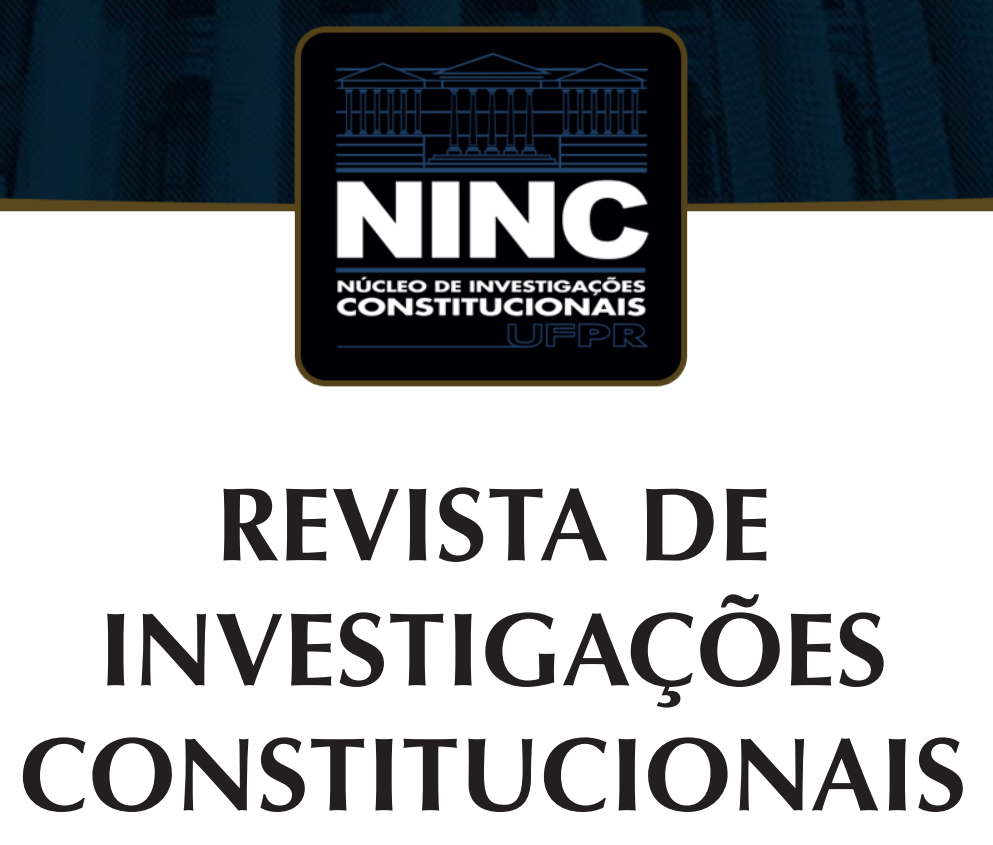

JOURNAL OF CONSTITUTIONAL RESEARCH

vol. 8 | n. 2 | maio/agosto 2021 | ISSN 2359-5639 | Periodicidade quadrimestral Curitiba | Núcleo de Investigações Constitucionais da UFPR | www.ninc.com.br 


\title{
Pro persona: fundamento y sentido de la primacía jurídica de la humanidad
}

\section{Pro persona: grounds and meaning of the legal primacy of humanity}

\author{
HUGO SAÚl RAMÍREZ I, * \\ 'Universidad Panamericana (Ciudad de México, México) \\ hugo.ramirez@up.edu.mx \\ https://orcid.org/0000-0001-9116-1341 \\ Recebido/Received: 26.07 .2020 / July $26^{\text {th }}, 2020$ \\ Aprovado/Approved: 20.12.2020 / December $20^{\text {th }}, 2020$
}

Resumen

Con el reconocimiento de los derechos humanos, el Estado de derecho adquiere el compromiso de orientar la praxis que legitima su existencia hacia la protección de los intereses fundamentales de todo ser humano. E principio pro persona es un elemento relevante en esta nueva faceta histórica del Estado de derecho, pues su aplicación tiene el potencial de encaminar la práctica jurídica hacia coordenadas que giran en torno a valores sustantivos. Teniendo en cuenta lo anterior, la cuestión central que se pretende comprender en este artículo apunta hacia el sentido y alcance del principio pro perso na partiendo de la siguiente pregunta: ¿dónde se localiza la justificación radical y objetiva de su validez?

Palabras clave: Derechos humanos; principio pro persona; teoría de la justicia; racionalidad jurídica; antropología filosófica.

\section{Abstract}

With the recognition of human rights, the rule of law is committed to guide the practice that legitimizes its existence towards the protection of the fundamental interests of every human being. The pro person principle is a prominent piece in this new historical stage of the rule of law, since its application has the potential to lead legal practice towards the achievement of substantive values. Considering the above, the central issue that this article seeks to understand points to the meaning and scope of the pro persona principle based on the following question: where is the radical and objective justification of its validity?

Keywords: Human rights; pro personae principle; theory of justice; legal rationality; philosophical anthropology.

Como citar esse artigo/How to cite this article: RAMíREZ, Hugo Saúl. Pro persona: fundamento y sentido de la primacía jurídica de la humanidad. Revista de Investigações Constitucionais, Curitiba, vol. 8, n. 2, p. 387-405, maio/ago. 2021. DOI: $10.5380 /$ rinc.v8i2.75450.

* Profesor de la Universidad Panamericana (Ciudad de México, México). Doctor en Derecho por la Universidad de Valencia. Licenciado en Derecho por la Universidad Nacional Autónoma de México. Miembro del Sistema Nacional de Investigadores del CONACYT, nivel 1. Profesor visitante en la Universidad Nacional Autónoma de México y en la Universidad de Valencia. E-mail: hugo.ramirez@up.edu.mx. 


\section{SUMARIO}

1. Introducción; 2. El principio pro persona: notas básicas; 3. Tres lecturas a propósito del fundamento y sentido del principio pro persona; 4. Una concepción de la justicia basada en los derechos humanos: contexto de alcance y aplicación para el principio pro persona; $\mathbf{5}$. Conclusiones; $\mathbf{6}$. Referencias.

\section{INTRODUCCIÓN}

¿Qué resulta del encuentro entre la práctica del Estado de Derecho y la práctica de los derechos humanos? Una noción lo expresa sintéticamente: la constitucionalización de la persona ${ }^{1}$. Esta expresión describe el profundo cambio que experimenta el Estado de derecho cuando adquiere el compromiso de orientar la praxis que legitima su existencia hacia la protección del ser humano: la persona constitucionalizada se convierte en el leitmotiv de lo jurídico, de lo público, etcétera. Este artículo ahonda en las implicaciones de este proceso de transformación del Estado de derecho enfocándose en el principio pro persona (en algunos contextos se denomina principio pro homine). En su formulación más simple el principio pro persona señala que ante la hipótesis de concurrencia de normas en un caso donde este implicada la adjudicación de un derecho humano, debe preferirse aquella cuya aplicación tenga como resultado la producción del estado de cosas más favorable para el titular del derecho en cuestión.

El conocimiento sobre el sentido de este principio es crucial porque su aplicación tiene el potencial de encaminar la práctica jurídica hacia cumplimiento cabal de los intereses fundamentales de todo ser humano. Teniendo en cuenta lo anterior, la cuestión central de este artículo apunta hacia el sentido del principio pro persona partiendo de la siguiente pregunta: ¿en dónde se localiza la justificación radical y objetiva de su validez? Contando con una respuesta sólidamente argumentada a esta cuestión, estaremos en mejores condiciones para comprender la posición de este principio, junto con otros como el de universalidad, progresividad, indivisibilidad, en el contexto de las tendencias con las que se pone de manifiesto una concepción o teoría de la justicia basada en los derechos humanos.

Con lo anterior en mente, el artículo se estructura en tres secciones. Comenzaré con algunas notas descriptivas del principio pro persona, con el afán de ubicar el modelo de adjudicación de derechos que impulsa su aplicación (apartado II). Describiré tres aproximaciones teóricas al principio pro persona que han intentado revelar su fundamento y su papel en el marco del discurso y la práctica contemporáneos de los derechos humanos (apartado III). Finalizaré exponiendo los elementos básicos de una teoría de la justicia centrada en los derechos humanos como el contexto en el que adquiere pleno sentido el alcance y la aplicación del principio pro persona (apartado IV).

SPAEMANN, Robert. Persons. The Difference Between 'Someone' and 'Something'. Oxford: Oxford University Press, 1998. p. 206. 


\section{EL PRINCIPIO PRO PERSONA: NOTAS BÁSICAS}

Comenzaré identificando un par de situaciones concretas en las que el principio pro persona tiene aplicación práctica: (a) Por un lado la preferencia normativa ${ }^{2}$ donde, ante un escenario de concurrencia de normas, se establece como deber la selección de la más favorable, o bien la menos restrictiva, para el goce efectivo de los derechos. (b) Por su parte, en la denominada preferencia hermenéutica ${ }^{3}$, ante varias interpretaciones posibles que dan como resultado la identificación de significados, contenidos y alcances múltiples para una determinada norma relativa a los derechos humanos, se establece el mandato para que el operador jurídico elija la alternativa más favorable para el titular del derecho en cuestión.

Como puede observarse, con su aplicación práctica el principio pro persona introduce una interpretación de la norma positiva orientada al bien, admitiendo que el lenguaje con el que ha sido formulada no siempre será lo suficientemente adecuado, o lo suficientemente claro para actualizarlo. Frente a esta realidad, corresponde al intérprete y aplicador ordenar las posibilidades y elegir la mejor opción.

Dicho lo anterior coincido con aquellos autores que han identificado en las denominadas cláusulas de favorabilidad un antecedente jurídico del principio pro persona ${ }^{4}$, aunque es necesario aclarar que las supera. Las cláusulas de favorabilidad son pautas que sugieren un sentido en la interpretación de ciertas normas, considerando el hecho de que su aplicación no puede ser ajena a la situación fáctica en la que se encuentran sus destinatarios; situación que por la naturaleza del lenguaje jurídico, puede escapar al redactor de la ley. Así, con fundamento en una atención más profunda y concentrada sobre la realidad, la cláusula de favorabilidad busca proteger a la parte más débil o vulnerable en una relación jurídica ante la posibilidad de causarle un mal o que deje de aprovechar un bien, dada su situación de desventaja. Son ejemplos típicos de cláusulas de favorabilidad las pautas in dubio pro reo; favor libertatis; in dubio pro operario, etcétera.

El principio pro persona, a semejanza de las cláusulas de favorabilidad, pretende la realización de un bien salvaguardado en una norma autorizando el ajuste de su aplicación a las peculiaridades específicas de la realidad implicada en el caso concreto; pero la supera porque no requiere para su aplicación que necesariamente se acredite la desventaja de alguien. Así, en tanto criterio de racionalidad, el principio pro persona legitima que la aplicación estricta de tal norma ceda espacio para tener en cuenta los

2 CASTILLA, Karlos. El principio pro persona en la administración de justicia. Cuestiones Constitucionales. Revista mexicana de Derecho constitucional, México, núm. 20, p. 65-83, 2009. p. 71.

3 CASTILLA, Karlos. El principio pro persona en la administración de justicia. Cuestiones Constitucionales. Revista mexicana de Derecho constitucional, México, núm. 20, p. 65-83, 2009. p. 72.

4 NOGUEIRA, Humberto. Teoría y dogmática de los derechos fundamentales. México: Universidad Nacional Autónoma de México, 2003. p. 76. 
escenarios donde se actualiza el mayor bien para el titular del derecho. El principio pro persona y las cláusulas de favorabilidad en todo caso están conectadas por su igual vocación hacia la epiqueya, ya que operan gracias a la distinción de los casos que superan la literalidad del discurso legal.

Por otro lado resulta importante señalar que varios instrumentos internacionales en la materia de derechos humanos han incorporado directrices que tienen como efecto la adopción del principio pro persona con el propósito de generar una salvaguarda efectiva y garantía mínima para tales derechos ${ }^{5}$. Ejemplos emblemáticos pueden encontrarse tanto en el Pacto Internacional de Derechos Civiles y Políticos, como en el Pacto Internacional de Derechos Económicos, Sociales y Culturales. En efecto, dentro de ambos instrumentos se establecen salvaguardas e incluso prohibiciones dirigidas a inhibir actos que tengan como resultado tanto la eliminación o anulación de cualquiera de los derechos y libertades en ellos reconocidos. Gracias a estas cláusulas los Estados parte admiten que un bien sustantivo justifica la vigencia y eficacia de la norma convencional, de tal manera que las interpretaciones o aplicaciones que tengan como consecuencia la vulneración de tal bien, deben tenerse como no jurídicas.

Por supuesto vale la pena apuntar que uno de los rasgos más destacados del principio pro persona es su formulación y desarrollo en sede judicial. En este sentido, si bien el principio pro persona ha sido incorporado en documentos jurídico-positivos como el artículo primero de la Constitución Política de los Estados Unidos Mexicano', su formulación conceptual y más originario empleo como criterio hermenéutico vinculante en materia de derechos humanos se localiza en la opinión separada dentro de la Opinión consultiva oc-7/86 del 29 de agosto de 1986, desahogada por la Corte Interamericana de Derechos Humanos, y postulada por el Juez Rodolfo Piza Escalante. En esa oportunidad fue reconocida la existencia de un criterio fundamental y vinculante de interpretación para las normas que recogen derechos humanos, derivado de su propia naturaleza. Así, cuando tales normas sean aplicadas se debe optar por el resultado hermenéutico más extenso, cuando se trata de definir las condiciones jurídicas de su goce; y por la conclusión normativa más restringida cuando el caso implica la limitación de su ejercicio.

Esta pieza jurídica postula una tesis de gran calado, a saber: si el derecho de los derechos humanos es una manifestación normativa del respeto que exige la persona

\footnotetext{
5 NIKKEN, Pedro, La protección internacional de los derechos humanos. Su desarrollo progresivo. Madrid: Civitas, 1987. p. 84.

$6 \quad$ El referido artículo establece textualmente: “En los Estados Unidos Mexicanos todas las personas gozarán de los derechos humanos reconocidos en esta Constitución y en los tratados internacionales de los que el Estado Mexicano sea parte, así como de las garantías para su protección, cuyo ejercicio no podrá restringirse ni suspenderse, salvo en los casos y bajo las condiciones que esta Constitución establece. Las normas relativas a los derechos humanos se interpretarán de conformidad con esta Constitución y con los tratados internacionales de la materia favoreciendo en todo tiempo a las personas la protección más amplia".
} 
con fundamento en su dignidad, entonces su sentido práctico apunta hacia una racionalidad de máximos, y no de mínimos. De tal forma que el imperativo eje de esta matriz de racionalidad práctica obliga al mayor respeto posible para la persona, de forma incondicional, así como a buscar el incremento permanente del desarrollo y bienestar para el titular de los derechos humanos.

En un contexto que culturalmente renuncia al bien como insumo primario de racionalidad, la comprensión adecuada del principio pro persona se torna difícil; más todavía cuando se insiste en que lo jurídico se define como la moral de mínimos por antonomasia ${ }^{7}$. Por lo anterior vale la pena ahondar en el sentido del principio pro persona, es decir, en las razones sobre las que se fundamenta validez, lo cual será el objetivo de las reflexiones que a continuación se exponen.

\section{TRES LECTURAS A PROPÓSITO DEL FUNDAMENTO Y SENTIDO DEL PRINCIPIO PRO PERSONA}

A la pregunta acerca de la finalidad que justifica la validez del principio pro persona se han propuesto varias respuestas. Cada una pondrá peculiar énfasis en algún aspecto que revela aquello que podemos esperar por su cumplimiento: la dotación de orden al tráfico jurídico complejo que acompaña al reconocimiento de los derechos humanos; el control sustantivo del poder; la realización óptima de los intereses fundamentales del ser humano. Veamos cada una de estas alternativas con mayor detalle.

\subsection{Pro persona y problemas lógicos del tráfico jurídico en materia de derechos humanos}

Comenzaré con una perspectiva para la que el fenómeno de la pluralidad de fuentes que alimentan al derecho de los derechos humanos, es el causante que justifica la validez del principio pro persona. Dicho con otros términos, la necesidad de su aplicación está en la búsqueda de criterios que faciliten, en el marco de un proceso de adjudicación, la elección de normas o de sus posibles interpretaciones, ante el problema de la pluralidad de fuentes a la que está expuesto el operador jurídico cuando tiene ante sí una cuestión relativa a los derechos humanos.

Para ahondar un poco más en este enfoque, acudo a la opinión que al respecto ha postulado Mónica Pinto. En un artículo de su autoría titulado "El principio pro homine. Criterios de hermenéutica y pautas para la regulación de los derechos humanos", explica que tal principio ha sido la respuesta a un sinfín de problemas provocados por

\footnotetext{
7 Ejemplo elocuente de lo anterior se encuentra en el pensamiento de Herbert Hart, quien sostiene que las coincidencias deónticas entre derecho y moral no se manifiestan como prestaciones activas, sino en prohibiciones. HART, Herbert. El concepto de derecho. Buenos Aires: Abeledo Perrot, 1995. p. 240.
} 
la aplicación del derecho de los derechos humanos el cual, a lo largo de las últimas décadas, se ha construido por normas internacionales bajo la forma de declaraciones, o de resoluciones de organismos internacionales, o de tratados con fórmulas susceptibles de generar el consentimiento de la mayoría de los Estados, etc., y por normas internas o locales, que, en más de una ocasión, se superponen en el tratamiento de cuestiones que presentan aspectos análogos ${ }^{8}$.

Es decir, el principio pro persona tiene como función primigenia la de dotar de orden al creciente tráfico jurídico en materia de derechos humanos, garantizando la coherencia formal de un sistema que, por el origen peculiar y estructura interna de sus normas, puede manifestar problemas de carácter lógico.

Así, según este enfoque, el principio pro persona es una norma de integración que, desde un punto de vista teleológico, garantizaría la seguridad jurídica en las operaciones de adjudicación de derechos humanos.

A mi juicio esta aproximación al sentido del principio pro persona revela un aspecto relevante, mismo que se centra en el énfasis con el que admite la presencia de una rica comunicación normativa que se da entre el derecho local o interno y el derecho internacional, a fin de resolver problemas de adjudicación de derechos humanos. Con ello abre la puerta al reconocimiento de la presencia de un solo derecho por razón de sus objetivos o fines (monismo jurídico), y no de dos sistemas normativos diversos y separados en razón de los peculiares criterios formales que dotan de validez a las normas que los componen (dualismo jurídico).

No obstante lo anterior, me parece que la mayor desventaja de esta línea de interpretación sobre el principio pro persona radica en su alta dependencia respecto de la formulación positiva del mismo. En efecto, si el principio pro persona comparte la misma finalidad de otras pautas con las que se resuelven casos de concurso de normas, entonces compartiría similares cuestionamientos en torno a su validez, ya que su capacidad para resolver casos de concurso de normas reposaría, fundamentalmente, en que así han sido establecidos por una norma positiva. Como explica Ricardo Caracciolo: respecto de principios como ley superior deroga inferior cabe preguntarse: ¿cuáles serían las razones que justifican la aceptación de esos principios y no otros, incluyendo los que podrían resultar de su inversión? Ante la ausencia de una respuesta satisfactoria que permita identificar que en todos los casos similares la ley jerárquicamente superior es auténticamente preferible a la inferior, se sigue que si estas pautas no se encuentran normativamente formuladas en el sistema, no existe ninguna razón para que el conflicto no se solucione de otra manera?.

8 PINTO, Mónica. El principio pro homine. Criterios de hermenéutica y pautas para la regulación de los derechos humanos. In ABREGU, Martín, (coord.). La aplicación de los tratados sobre derechos humanos por los tribunales locales. Buenos Aires: Ediciones del Puerto, 1997. p. 163.

9 CARACCIOLO, Ricardo. La noción de sistema en la teoría del derecho. México: Fontamara, 1999. p. 22. 
De esta forma, para tal perspectiva la validez del principio pro persona se encuentra supeditada a su positivación; luego los derechos humanos, por sí mismos, no generan la exigencia de interpretación normativa orientada a dotar de mayores bienes en favor de su titular. En consecuencia, si el principio pro persona no se encuentra recogido en una norma positiva, se mantendrían los criterios estrictamente formales para la solución de problemas de concurrencia de normas en materia de derechos humanos.

Más aún, llevando al extremo esta postura podría resultar que si no hay normas concurrentes, esto es, una más protectora y otra menos protectora de un derecho humano, no hay aplicación del principio pro persona. O sea, si acaso nos encontramos con una norma que brinda una pobre protección de los derechos, que no puede ser contrastada con otra, el principio no opera y, por lo tanto, no se logra el propósito de optimizar el bien inherente a aquellos.

\subsection{El principio pro persona como medio de control del poder}

Según el enfoque que sostienen autores como Fernando Silva García, la aplicación del principio pro persona pretende un objetivo de carácter político, ya que se trata de una norma integrada al sistema público del control del poder. Su principal cometido es garantizar que la democracia sustantiva prevalezca en caso de conflicto frente a la democracia formal ${ }^{10}$ tal y como se pretende con otros mecanismos, como es el caso de una cláusula de intangibilidad.

El marco teórico y filosófico de esta lectura política del principio que nos ocupa es el garantismo jurídico. A continuación reconstruyo algunas de sus principales tesis para comprender mejor qué significa que el principio pro persona sea una herramienta para controlar el poder.

El garantismo jurídico se arraiga en una convicción acerca del ejercicio del poder según la cual hay que esperar de él siempre un potencial abuso que es preciso neutrali$z{ }^{11}$. Con este punto de partida lo jurídico es descrito como un sistema normativo que establece límites al poder, concretamente: un sistema artificial de garantías. Dentro del sistema artificial de garantías los derechos fundamentales tienen un papel protagónico pues representan la traducción técnico-jurídica de una decisión política con la cual se imponen límites al ejercicio del poder tanto en el espacio público como en el privado, aprovechando la forma universal, inalienable, indisponible y constitucional para tutelar aquello que se ha considerado, políticamente, como fundamental ${ }^{12}$.

10 SILVA, Fernando y SÁMANO, José. Principio pro homine vs restricciones constitucionales: ¿Es posible constitucionalizar el autoritarismo? Revista del Instituto de la Judicatura Federal. México, núm. 37, p. 235-268, 2014. p. 246-47.

11 FERRAJOLI, Luigi. El derecho como sistema de garantías. Jueces para la democracia, n. 16/17, p. 61-69, 1992. p. 62.

12 FERRAJOLI, Luigi. Derechos y garantías. La ley de más débil. Madrid:Trotta, 2001. p. 51. 
Si las instituciones jurídicas tienen una vocación marcadamente política, entonces la judicatura está vinculada al cumplimiento del objetivo general de control del poder; concretamente a través de la aplicación de la norma constitucional donde, sabemos, se alojan los derechos fundamentales ${ }^{13}$. Para lograr tal cometido, la función judicial cuenta con diversos mecanismos como, por ejemplo, la independencia respecto de otros poderes a los que debe controlar. Precisamente dentro de tal conjunto de realidades con las que la judicatura controla al poder y custodia las decisiones fundamentales de la democracia sustancial, se encuentra el principio pro persona. Empleando la nomenclatura afín al garantismo jurídico, nuestro principio formaría parte del entramado institucional con el que se configuran las denominadas garantías secundarias que, como puede recordarse, mantienen una función subsidiaria respecto de las garantías primarias (que incumben al legislador y la producción de normas generales), operando sólo en caso de insuficiencia o incumplimiento en aquellas.

Si bien no comparto la desconfianza radical y sistemática que caracteriza al garantismo respecto del ejercicio del poder, creo que representa un acierto definir claramente sus límites para evitar y contrarrestar situaciones de arbitrariedad: el derecho juega un papel fundamental en esta tarea, como tendremos ocasión de ver posteriormente. No obstante lo anterior esta perspectiva manifiesta importantes debilidades cuando sostiene que aquello que debemos esperar de la aplicación del principio pro persona es un eficiente ejercicio de control del poder, sobre todo porque se obstaculiza la capacidad de humanización de lo jurídico a la que, en mi opinión, está llamado el principio pro persona.

Lo afirmado se acredita cuando consideramos que, bajo la óptica del garantismo, el principio pro persona gira en la órbita de racionalidad de los derechos fundamentales, y su alcance está condicionado por lo que tales derechos significan realmente. Recordemos que los derechos fundamentales son derechos subjetivos (con contenidos prestacionales o de inmunidad), cuyo alcance dependerá del status de persona adscrito a un sujeto por mediación de una norma positiva ${ }^{14}$.

De lo anterior se sigue que el principio pro persona sólo es relevante para salvaguardar el contenido de una decisión política que ha tomado la forma de una norma positiva; ésta, a pesar de ser constitucional, no deja de ser contingente ya que su fundamento reposa en un consenso que siempre puede mudar. En este punto, el garantismo y su visión del principio pro persona no logran separarse de la tesis kelseniana que describe al escepticismo filosófico y al relativismo ético como condiciones de posibilidad de la democracia, reducida a regla de la mayoría. En palabras de Hans Kelsen: "sólo si no existe el bien absoluto puede justificarse el legislar: el determinar los contenidos del

13 FERRAJOLI, Luigi. Las fuentes de legitimidad de la jurisdicción México: Instituto Nacional de Ciencias Penales, 2010. p. 26.

14 FERRAJOLI, Luigi. Derechos y garantías. La ley de más débil. Madrid:Trotta, 2001. p. 37. 
ordenamiento jurídico, no ya según lo objetivamente mejor para los individuos, sino según lo que estos individuos, en su mayoría por lo menos, creen, con razón o sin ella, qué es lo mejor"15.

Bajo esta perspectiva la puesta en práctica del principio pro persona poco tiene que ver con la búsqueda y actualización de la verdad ontológica sobre bien humano, y en consecuencia se torna indiferente respecto del quid ius por la subordinación que tiene respecto de la positividad de la norma, como formalización de la voluntad. Una pregunta ayuda a comprender este punto. ¿Si el principio pro persona no estuviese positivamente estipulado en la norma, por ejemplo en una constitución, sería una garantía, o sería jurídicamente estéril? Para el garantismos la respuesta es: no es una garantía, y por tanto es jurídicamente estéril. Adicionalmente, la lectura garantista compromete la capacidad incluyente del principio pro persona, ya que la universalidad de los derechos fundamentales se equipara a la generalidad de la norma jurídica: es decir, ligado a los derechos fundamentales, el principio pro persona sólo opera a favor de aquellos sujetos a los que el legislador, a través de la norma jurídica positiva, les atribuye el estatus de persona y titular de los derechos ${ }^{16}$.

\subsection{Pro persona: primacía jurídica de la humanidad}

Hasta ahora hemos hecho un recorrido puntual por dos lecturas acerca de la finalidad del principio pro persona. Ambas, a mi juicio, inadvierten aquello que realmente le dota de sentido; y ello a causa de las premisas con las cuales emprenden sus respectivos ejercicios hermenéuticos. Resultados diferentes se pueden obtener si tales premisas son sustituidas por otras de matriz antropológica. Es lo que haré a continuación apoyándome en el pensamiento de Jesús Ballesteros. Quisiera comenzar con una afirmación postulada por el Profesor Ballesteros en Sobre el sentido del Derecho: "Ia antropología filosófica, el conocimiento de los caracteres existenciales del ser del hombre, constituye el punto de partida necesario para la pregunta acerca del sentido o sinsentido del derecho en la vida"17.

15 KELSEN, Hans. ¿Qué es justicia? Barcelona: Planeta- De Agostini, 1993. p. 123.

16 En la actualidad, y como consecuencia del amplio influjo que ha tenido la revisión del concepto persona (el denominado personismo) sobre la producción normativa y la interpretación jurídica, no faltan ejemplos de exclusión sobre individuos de la especia humana que no son considerados personas y por tanto negada su carácter de titulares de los derechos humanos, en razón de la construcción lingüística de una ley, o bien en razón de su interpretación; considero un ejemplo de lo anterior la sentencia que emitió la Corte Interamericana de Derechos Humanos al conocido como Caso Artavia Murillo vs Costa Rica. Un recuento sobre el debate que ha suscitado la revisión del concepto persona y sus efectos prácticos se encuentra en: BURGOS, Juan. Persona versus ser humano: un análisis del esquema argumentativo básico del debate. Cuadernos de Bioética, vol. XIX, núm. 3, septiembre-diciembre, p. 433-447, 2008.

17 BALLESTEROS, Jesús. Sobre el sentido del derecho. Introducción a la filosofía jurídica. Madrid, Tecnos, 2001. p. 123. 
En estas líneas queda claramente asentada la que considero como la ruta adecuada para dar respuesta a la cuestión clave de la filosofía del derecho, a saber: cuál es la causa radical de su existencia y, en consecuencia, cuál es la fuente de justificación última de validez para las normas que lo integran.

Así se nos advierte que la viabilidad misma de la reflexión filosófica sobre el derecho depende de esta asociación, ya que las tesis parciales y reduccionistas cometen el error epistemológico de obviar los datos que singularizan al ser humano en el momento de pensar la génesis del derecho.

Asentada la importancia que tiene el dato antropológico para la filosofía jurídica, en la reflexión de Jesús Ballesteros ese dato sería el de la alteridad. Es decir, la existencia realmente humana se manifiesta ahí donde el sujeto experimenta la alteridad. Es decir, cuando recibe ayuda y asistencia de otros para lograr el propio florecimiento, así como cuando actúa siendo consciente de la relevancia de sus actos en la existencia de sus semejantes; en definitiva, apertura existencial a la realidad ${ }^{18}$. Dicho con otras palabras, la alteridad significa que la existencia del ser humano es condición de posibilidad del bien para otros seres humanos: esta es la raíz antropológica de la interdependencia y la complementariedad y, claro, la justicia ${ }^{19}$.

El siguiente paso es saber cómo se explica la presencia del derecho en la existencia humana, atendiendo a la tesis antropológica previamente expuesta. La clave que nos ofrece el Profesor Ballesteros está en el reconocimiento de que la apertura existencial a la alteridad, como verdad del ser humano, no es un dato teórico, sino que es un motivo radical para la acción. De esta manera el derecho justifica su existencia, y encuentra la causa de validez última de las normas que lo componen cuando motiva autoritativamente (con las garantías de la coactividad) la realización de conductas con las que se respeta, incondicionalmente, al otro. Con otros términos la existencia de lo jurídico se justifica si contribuye a cerrar la brecha entre el plano ontológico del existir humano, y su concreción óntica, o si se prefiere histórica, mediante actos libres de respeto y cuidado de los semejantes ${ }^{20}$.

\footnotetext{
18 Las tesis antropológicas del Profesor Ballesteros están inspiradas en las reflexiones de Heidegger para quien exisitir, estar presente: Dasein, consiste en Ex-sistenz: estar no en sí, sino en el ser.

19 A semejantes tesis ha llegado Alasdair Maclntyre cuando afirma: “El cuidado de los demás desempeña un papel fundamental para mantener la vida en común (...). El ser humano puede desestimar este hecho o puede ocultárselo a sí mismo, imaginándose como una persona lockeana o una mente cartesiana o incluso como un alma platónica; pero también, tiene la posibilidad de entender su identidad (dependiente) a través del tiempo, desde la concepción hasta la muerte, y entender con ello su necesidad de contar con el cuidado de otras personas en diferentes etapas de la vida pasada y futura. Es decir, sabe que ha recibido atención y cuidado, y sabe que se espera que a su vez preste esos cuidados de vez en cuando; y sabe que habiéndose ocupado de cuidar a otros, tendrá necesidad, también de vez en cuando, de que los demás le cuiden". MACINTYRE, Alasdair. Animales racionales y dependientes. Por qué los seres humanos necesitamos las virtudes. Barcelona: Paidós, 2001. p. 100-01.

20 El núcleo del fin del derecho, de su practicidad, se formula según nuestro autor como: "el respeto universal al otro, la vieja idea de humanitas, que reaparece en Kant: la exigencia de tratar al otro siempre como fin
} 
Esto vale para la experiencia jurídica como un todo; y con mayor razón para la directamente asociada a los derechos humanos. En efecto, una justicia con base en la alteridad es más intensa debido al carácter universal de aquellos. Como todos sabemos la universalidad de los derechos se predica principalmente respecto de la titularidad: todos los seres humanos son titulares de todos los derechos. Aquí el Profesor Ballesteros da un paso más y propone la noción de "conciencia de universalidad": se trata de una realidad moral basada en el reconocimiento de la paridad ontológica entre el yo y el otro, en pos de la fidelidad de las acciones en cuanto que son relevantes para alcanzar el bien humano ${ }^{21}$.

Tal interpretación de la universalidad, como conciencia moral radical, nos muestra a los derechos como realidades mancomunadas. Con ellos se integra y robustece una tupida red de reciprocidades, cuyo objeto es el respeto y la concreción del bien, de tal manera que la fuerza de los derechos dependerá de la fuerza de esta red. Siendo plenamente consciente de todo esto, el profesor Ballesteros advierte, de manera constante, acerca de los peligros que acechan a esta moral genuina, y nos invita a reconocer que lo jurídico debe asumir aquí una importante función: la de auxiliar al ser humano a mantener lealmente una fidelidad duradera respecto al hecho de ser condición de posibilidad del bien de otros ${ }^{22}$.

Haciendo acopio de ideas, contamos con mejores claves para comprender la justificación de la existencia y aplicación del principio pro persona el cual, recordemos brevemente, establece el mandato de elegir la norma o su interpretación que tenga como resultado la producción de un estado de cosas más favorable para el titular de un derecho humano.

En primer lugar, la aplicación del principio pro persona representa un interesante episodio de rehabilitación de la razón práctica, ya que genera un fuerte incentivo para incrementar el conocimiento sobre el bien humano, y la mejor manera de orientar la conducta hacia su obtención. Es decir, el principio pro persona no podría ser imperativo si antes y al mismo tiempo no estuviese cognoscitivamente abierto al ser. Dicho con Carlos Massini, "no sería la medida del obrar, si no recibiese antes y al mismo tiempo su medida de la realidad objetiva (...); de aquello que el hombre es y de las concretas circunstancias en las que debe poner su acto libre y racional"23.

y nunca como medio, (lo cual se concreta): en la exclusión de la discriminación (...), y de la violencia, en sus diversas formas". BALLESTEROS, Jesús. Sobre el sentido del derecho. Introducción a la filosofía jurídica. Madrid: Tecnos, 2001. p. 128.

21 BALLESTEROS, Jesús. Sobre el sentido del derecho. Introducción a la filosofía jurídica. Madrid: Tecnos, 2001. p. 111.

22 BALLESTEROS, Jesús. Sobre el sentido del derecho. Introducción a la filosofía jurídica. Madrid: Tecnos, 2001. p. 131.

23 MASSINI, Carlos. La prudencia jurídica. Introducción a la gnoseología del Derecho. Buenos Aires: Abeledo-Perrot, 1984. p. 182. 
Por otro lado, el mandato del principio pro persona fomenta la concreción de la universalidad de los derechos en cuanto a la intensidad del respeto a la dignidad de la persona. Lo hace admitiendo que el discurso normativo es imperfecto y no agota las formas en las que puede realizarse el bien humano. También lo hace exigiendo al operador jurídico encargado de aplicar la norma de derechos humanos que, en cada caso, ponga suficiente atención en las específicas situaciones vitales que manifiesta su titular. Con ello, el principio pro persona puede resultar de gran relevancia para el desarrollo del denominado por la Profesora Encarnación Fernández como "proceso de especificación de los derechos humanos": conectando las exigencias abstractas de respeto, con las situaciones particulares de las personas que pueden requerir un tratamiento especial ${ }^{24}$.

Finalmente, en su significado antropológico más profundo, el principio pro persona también nos llama a ser fieles y leales en el esfuerzo por abrir la cotidiana tópica jurídica, en una utopía atesoradora de exigencias de lo humano. Esto puede ser traducido en la defensa permanente de la titularidad universal de los derechos humanos ante las interpretaciones que facilitan su estrechamiento sólo a aquellos sujetos que cumplen con determinadas condiciones; ese sería el caso de considerar a los derechos sólo como el resultado de decisiones políticas, por más fundamentales que sean. Frente a esto, el Profesor Ballesteros ha insistido en distinguir entre el ser y el tener cuando se trata de derivar consecuencias prácticas desde la dignidad humana: "el ser humano existe antes de poseer los indicadores humanos o propiedades (conciencia, capaz de sufrimiento, autonomía), porque tales cualidades afectan al tener del hombre y no a su ser, y por tanto no son notas universales" 25 . Apoyados en esta tesis es posible afirmar que una de las primeras aplicaciones del principio pro persona será la de dirigir toda interpretación de normas en materia de derechos humanos a evitar cualquier restricción del conjunto de sus titulares, y en cambio incluir primero a los más indigentes, dependientes, vulnerables y desnudos.

\section{UNA CONCEPCIÓN DE LA JUSTICIA BASADA EN LOS DERECHOS HUMANOS: CONTEXTO DE ALCANCE Y APLICACIÓN PARA EL PRINCIPIO PRO PERSONA}

La última etapa de mi reflexión se dedica a mostrar los elementos básicos de una concepción de la justicia donde los derechos humanos, considerados como una práctica coherente, validan parámetros de racionalidad práctica (y consecuentemente de racionalidad jurídica); y en esa medida, revelan el contexto de alcance y sentido para el principio pro persona.

24 FERNÁNDEZ, Encarnación. Igualdad y derechos humanos. Madrid: Tecnos, 2003. p. 51.

25 BALLESTEROS, Jesús. Sobre la fundamentación antropológica de la universalidad de los derechos humanos. Valencia: Real Academia de Cultura Valencia, 1999. p. 24. 
Una concepción o teoría de la justicia busca resolver cuestiones relativas a cómo deberían tratarse los individuos entre sí; a cómo deberían distribuirse los bienes que se obtienen y conservan gracias al esfuerzo de los miembros de la sociedad; a cómo debería configurarse el contenido de las normas vinculantes en esa misma sociedad. Comencemos en un nivel conceptual: justicia expresa el criterio de valoración más alto respecto de la corrección de conductas y normas dentro del plano intersubjetivo de compensación y distribución de bienes. "Quien afirma que algo es justo, afirma siempre y de algún modo, al mismo tiempo, que es correcto. Y quien afirma que algo es correcto sobreentiende que es susceptible de ser fundamentado, justificado mediante razones" ${ }^{\prime 26}$. Justicia es, entonces, el atributo predicable a las conductas y normas cuya realización y validez, respectivamente, está justificada-fundamentada en su corrección.

¿Qué hace realmente a una conducta o a una norma justas-correctas? Las concepciones de lo justo se distinguen unas de otras por las características que proponen para aquello que merece ser juzgado como correcto, así como el camino para llegar a tal conclusión. La concepción de lo justo basada en los derechos humanos gira en torno a un axioma que establece lo siguiente: por el hecho de ser y como condición necesaria para realizarse qua seres humanos, todos los individuos de la especie humana son titulares de un conjunto de bienes, prerrogativas e inmunidades que representan sus intereses fundamentales, impostergables e incondicionados ${ }^{27}$.

A partir de este axioma se sigue: (i) que la existencia de un sistema de normas positivas está justificada para garantizar el respeto y disfrute de los bienes, prerrogativas e inmunidades inherentes a los derechos; (ii) que las normas son justas y por lo tanto coactivamente vinculantes si y sólo si su cumplimiento protege y promueve los intereses fundamentales de todos los seres humanos; (iii) que el criterio de corrección y justicia para los actos distributivos y correctivos coincide con el grado de respeto, protección y promoción de los intereses fundamentales de todos los seres humanos.

La realización del axioma de los derechos humanos y sus implicaciones prácticas impulsa tendencias que dan forma a la praxis jurídica contemporánea, tanto a nivel nacional como internacional. Desde mi punto de vista esas tendencias son: (a) la ampliación del contexto de juridicidad de una conducta: del nexo con la ley a la relación entre personas; (b) la consolidación del imperativo por eliminar situaciones de discriminación; (c) la integración de la matriz de racionalidad de lo jurídico con la matriz de racionalidad de los intereses humanos fundamentales; (d) la superación de los obstáculos que inhiban la realización de los intereses humanos fundamentales; (e) el cumplimiento de la promesa moral de los derechos humanos. Analicemos a continuación cada una de estas tendencias.

26 ALEXY, Robert. Justicia como corrección. Doxa. Cuadernos de Filosofía del Derecho, n. 26, p. 161-171, 2002. p. 163.

27 HIERRO, Liborio. Los derechos humanos. Una concepción de la justicia. Madrid: Marcial Pons, 2016. p. 53. 
(a) Respecto de la primera tendencia arriba anunciada puede observarse que, en razón de los derechos humanos, el propósito del cumplimiento de un amplio sector de deberes jurídicos adquiere una renovada claridad. Efectivamente, desde que los derechos humanos son reconocidos e institucionalizados conviven obligaciones jurídicas cuyo cumplimiento logra un objetivo (pensemos en el objetivo de establecer el horario comercial en una ciudad), y obligaciones jurídicas cuyo cumplimiento realiza un fin: la realización plena de cada ser humano. El deber vinculado a un derecho humano, explica Ernest Tugendhat ${ }^{28}$, deviene una obligación en el sentido originario del término: por virtud de tal obligación el responsable de su cumplimiento se encuentra unido o ligado al bien del titular del derecho. A este tipo de vínculo Habermas lo denomina relación moral. Aquí una persona vinculada a otra se pregunta lo que le debe prescindiendo completamente de cuál sea la relación social en que se encuentra respecto a ella, de cuál pueda ser su comportamiento o lo que de ella pueda esperar ${ }^{29}$.

Con los derechos humanos nos situamos ante una forma de justicia cualificada por el valor inconmensurable de su titular. Esto debe llevarnos a considerar que el incumplimiento de una obligación basada en normas ordinarias puede ser compensado, mientras que el incumplimiento de una obligación vinculada a un derecho humano provoca un daño que en no pocas ocasiones puede ser irremediable.

(b) La segunda tendencia impulsada por la concepción de la justicia fundada en los derechos humanos propaga, con una intensidad sin precedente histórico, el deber de trato igual para todos. Hoy es un principio moral indisputado la proscripción de las discriminaciones primarias, es decir, aquellas que niegan el igual valor de todo ser humano. Por otro lado, y con el mismo propósito inclusivo, se autorizan las distinciones secundarias; es decir, aquellas que suponen una distribución desigual de bienes justificada por el mismo respeto hacia todos. En ambos casos queda claro que la dignidad humana está presente en cada ser humano concreto, de tal forma que resulta un imperativo actualizar la universalidad de los derechos atendiendo a la pluralidad de modos en que se manifiesta el ser del ser humano ${ }^{30}$.

(c) Durante un dilatado periodo de tiempo las tesis de Hobbes sobre la justicia como legalidad fueron hegemónicas en el diseño y realización de lo jurídico. Recordemos que en la perspectiva hobbesiana de la justicia tiene primacía la positividad de las leyes. Lo justo se predica de un acto que se ajusta a lo prescrito en la ley, pero ésta no es ni justa ni injusta. Se trata de la conocida como no-rights thesis donde lo jurídico, en su afán de certeza, no compromete su validez con contenidos sustantivos, como

\footnotetext{
28 TUGENDHAT, Ernest. Justicia y Derechos humanos. Barcelona: Publicacions Universitat de Barcelona, 1993. p. 15

29 HABERMAS, Jürgen. The concept of human dignity and the realistic utopia of Human rights. In CORRADET-

TI, Claudio, (edt.). Philosophical Dimensions of Human Rights. Heidelberg: Springer, 2012, p. 77.

30 FERNÁNDEZ, Encarnación. Igualdad y derechos humanos. Madrid: Tecnos, 2003. p. 49.
} 
los derechos humanos, de tal manera que puede ser completamente válido-vinculante-coactivo aún cuando legalice la esclavitud u otras formas graves de vulneración de la dignidad humana ${ }^{31}$.

La tendencia emergente es diametralmente opuesta y ha implicado una reinterpretación de la certeza jurídica. Claro ejemplo de esto se encuentra en las reflexiones de Aulis Aarnio ${ }^{32}$ sobre el razonamiento jurídico. Antes de los derechos el valor de tal certeza jurídica reposaba únicamente en la posibilidad de anticipación sobre la base de una práctica previsible. De acuerdo con esta formulación, certeza jurídica es el antídoto contra la arbitrariedad de la discrecionalidad. A partir de la incorporación de los derechos humanos en la práctica jurídica cotidiana la certeza del derecho ya no descansa exclusivamente en la forma, sino que abraca dos elementos: un razonamiento jurídico no arbitrario que concreta el principio de legalidad y la obtención de un bien sustantivo que es provisto por los derechos humanos. Con esto las prioridades del Estado de derecho se enfocan en garantizar la calidad de vida y, coherentemente con ello, proteger al más débil en cualquier relación social ${ }^{33}$.

(d) En abril de 1966 Theodor Adorno abre la célebre conferencia La educación después de Auschwitz con la siguiente tesis: "La exigencia de que Auschwitz no se repita es la primera de todas en la educación. Hasta tal punto precede a cualquier otra que no creo deber ni poder fundamentarla". Estas palabras sintetizan la cuarta tendencia sobre la que quisiera reflexionar: la superación de los obstáculos que impidan el respeto y la realización de los intereses fundamentales inherentes a los derechos humanos. Se trata del propósito civilizatorio que resulta de haber reconocido los derechos y que se traduce en la lucha permanente contra la injusticia para concretar la justicia. Con palabras de Luis Villoro: "la injusticia es una carencia experimentada de valor objetivo; de esa experiencia puede partir la proyección, basada en razones, de una situación posible en que se daría ese valor" ${ }^{\prime 3}$.

Entre los obstáculos que se levantan contra los derechos humanos hay uno que, desde mi punto de vista, resulta particularmente pernicioso: su trivialización moral. Por trivialidad moral entiendo la pérdida de capacidad de los derechos para transformar positivamente a las sociedades donde se han reconocido, e incluso la pérdida de capacidad para mantener el ritmo de reconocimiento global que hasta ahora han desarrollado. Uno de los fenómenos que la propicia es la incapacidad para distinguir entre

31 FOX-DECENT, Evan. Is the Rule of Law really indifferent to Human rights? Law and Philosophy, vol. 27, p. 533-581, 2008. p. 533.

32 AARNIO, Aulis. La tesis de la única respuesta correcta y el principio regulativo del razonamiento jurídico. Doxa. Cuadernos de Filosofía del Derecho, n. 8, p. 23-38, 1990. p. 25.

33 AARNIO, Aulis. La tesis de la única respuesta correcta y el principio regulativo del razonamiento jurídico. Doxa. Cuadernos de Filosofía del Derecho, n. 8, p. 23-38, 1990. p. 26.

34 VILLORO, Luis. Sobre el principio de injusticia: la exclusión. Isegoría. Revista de Filosofía, Moral y Política, n. 22, p. 103-142, 2000. p. 105. 
auténticos e inauténticos derechos; entre reivindicaciones que se asientan verdaderamente en intereses humanos fundamentales y las que no. Como lo explica John Tasioulas: "Para evitar que los derechos humanos sean víctimas de su propia popularidad se requiere de una forma organizada, conforme a principios, para distinguir a los derechos verdaderos de la supuesta avalancha de derechos falsos" ${ }^{\prime \prime 3}$.

Por razones de espacio este no es lugar para ahondar en esta cuestión. Sin embargo, vale la pena tener conciencia del problema para superarlo oportunamente. Mientras tanto adelanto que una estrategia para realizar la distinción entre derechos auténticos e inauténticos se sitúa en el contexto de su adjudicación. Como sabemos, la adjudicación es contexto de emergencia de colisión entre derechos. En efecto, éstos "son en cierta medida exclusivos, pues cada uno exige la excelencia en la garantía de un bien; son plurales pues son muchos los bienes a garantizar; pero, simultáneamente, no pueden ser tutelados unos en detrimento de otros" ${ }^{\prime \prime 36}$. Admitiendo lo anterior, en el momento de su adjudicación los derechos demuestran su autenticidad si son compatibles con el ejercicio de otros derechos. O con términos de Isabel Trujillo: los derechos son jurídicamente razonables y por tanto verdaderos cuando no excluyen a otros derechos ni a otros principios jurídicos ${ }^{37}$. Esto es crucial para la universalidad y la indivisibilidad de los derechos humanos: simple y llanamente tal compatibilidad es la garantía radical para el ejercicio de los derechos de todos, y por tanto del imperativo de trato igual. Los supuestos derechos que se manifiestan incompatibles con el ejercicio de otros derechos no son razonables, por lo que realmente son falsos derechos o no-derechos. En síntesis, los derechos humanos auténticos son aquellos que tutelan intereses fundamentales sin cancelar otros intereses fundamentales; de ello puede derivarse un principio: ningún derecho humano debe ser absolutamente sacrificado en favor del apoyo o promoción de otro derecho humano ${ }^{38}$.

(e) De capital importancia para la concepción de la justicia basada en los derechos humanos es la tendencia que apunta al cumplimiento de su promesa moral ${ }^{39}$. Consiste en realizar, con el mayor grado de perfección posible, el sustrato normativo

35 TASIOULAS, John. La realidad moral de los derechos humanos. Anuario de Derechos humanos, n. 4, p. 41-67, 2011. p. 41.

36 TRUJILLO, Isabel. Derechos y falsos derechos: Derechos razonables y no razonables. Persona y Derecho, n. 52, p. 219-236, 2005. p. 230.

37 TRUJILLO, Isabel. Derechos y falsos derechos: Derechos razonables y no razonables. Persona y Derecho, n. 52, p. 219-236, 2005. p. 231. Debemos aclarar que, en el contexto de este argumento, excluir no significa limitar. La exclusión sería una eliminación absoluta de las posibilidades de ejercicio de un derecho. La limitación de un derecho, por su parte, modera su ejercicio contando con razones que de forma solvente así lo justifican. La resolución razonable o de compatibilidad de controversias en las que se ven involucrados derechos humanos buscaría la limitación fundamentada cuando el caso lo amerite.

38 TRUJILLO, Isabel, y VIOLA, Francesco. What Human Rights are not (or not only). A negative path to human rights practice. Nueva York: Nova Publishers, 2014. p. 13.

39 HABERMAS, Jürgen. The concept of human dignity and the realistic utopia of Human rights. In CORRADET-

TI, Claudio, (edt.). Philosophical Dimensions of Human Rights. Heidelberg: Springer, 2012, p. 63-80. p. 80. 
de la igual dignidad de cada ser humano y de los bienes que atañen a sus intereses fundamentales. El principio pro persona se encuentra directamente asociado a esta tendencia porque exige al aplicador de la norma la extracción continuada del contenido normativo adecuado, para lograr el estado de cosas donde el titular aproveche el bien inherente de cada derecho en forma óptima. En una resolución donde se aplica el principio pro persona se actualiza la utopía realista que Habermas atribuye a los derechos humanos; no es una imagen engañosa del bien, sino la realización auténtica de la justicia en un caso concreto.

\section{CONCLUSIONES}

Llegados a este punto podemos realizar un balance acerca de las reflexiones que ha suscitado el sentido del principio pro persona, a través de las siguientes ideas:

a. La presencia del principio pro persona en la práctica jurídica contemporánea no puede pasar desapercibida. La manera en que se piensa y vive el derecho no es la misma una vez que consideramos seriamente las consecuencias que apareja su aplicación: a las fortalezas de la racionalidad jurídica ligadas a la forma, y que se desahogan bajo la subsunción, se suman las que se orientan al bien y que requieren del operador jurídico otros insumos y estrategias intelectuales, como la valoración y la argumentación.

b. Las aproximaciones teóricas al principio pro persona que hacen hincapié en sus expedientes lógico-formal y político revelan la complejidad del mismo. Sin embargo no logran captar su sentido más profundo y radical. En cambio, bajo la óptica de la antropología filosófico-jurídica pudimos observar que el cumplimiento del principio pro persona puede leerse como una inmejorable oportunidad para afirmar la primacía de lo humano en la realidad jurídica. En este caso, el bien inmanente a la práctica del principio pro persona se encuentra en el robustecimiento de la fidelidad a cargo de todos (y en primera fila las autoridades públicas) para contribuir a logro de los intereses fundamentales de todo ser humano, gracias a una interpretación y aplicación de las normas jurídicas que dan prioridad a la justicia sustantiva sobre otros criterios de racionalidad.

c. Una concepción de la justicia basada en los derechos humanos representa el marco general de racionalidad práctica donde mejor se aloja el principio pro persona, pues es ahí donde se revela con toda claridad su vocación hermenéutica: orientada a la extracción continua del contenido normativo adecuado, en pos del mayor bien para el titular del derecho. 


\section{REFERENCIAS}

AARNIO, Aulis. La tesis de la única respuesta correcta y el principio regulativo del razonamiento jurídico. Doxa. Cuadernos de Filosofía del Derecho, n. 8, p. 23-38, 1990.

ALEXY, Robert. Justicia como corrección. Doxa. Cuadernos de Filosofía del Derecho, n. 26, p. 161-171, 2002.

BALLESTEROS, Jesús, Sobre la fundamentación antropológica de la universalidad de los derechos humanos. Valencia: Real Academia de Cultura Valencia, 1999.

BALLESTEROS, Jesús. Sobre el sentido del derecho. Introducción a la filosofía jurídica, Madrid: Tecnos, 2001.

BURGOS, Juan. Persona versus ser humano: un análisis del esquema argumentativo básico del debate. Cuadernos de Bioética, vol. XIX, núm. 3, septiembre-diciembre, 2008, p 433-447.

CARACCIOLO, Ricardo. La noción de sistema en la teoría del derecho. México: Fontamara, 1999.

CASTILLA, Karlos. El principio pro persona en la administración de justicia. Cuestiones Constitucionales. Revista mexicana de Derecho constitucional, México, núm. 20, p. 65-83, 2009.

FERNÁNDEZ, Encarnación, Igualdad y derechos humanos, Madrid: Tecnos, 2003.

FERRAJOLI, Luigi, Derechos y garantías. La ley de más débil. Madrid: Trotta, 2001.

FERRAJOLI, Luigi. El derecho como sistema de garantías. Jueces para la democracia, n. 16/17, p. 61-69, 1992.

FERRAJOLI, Luigi. Las fuentes de legitimidad de la jurisdicción. México: Instituto Nacional de Ciencias Penales, 2010.

FOX-DECENT, Evan. Is the Rule of Law really indifferent to Human rights? Law and Philosophy, vol. 27, p. 533-581, 2008.

HABERMAS, Jürgen. The concept of human dignity and the realistic utopia of Human rights. In CORRADETTI, Claudio, (edt.). Philosophical Dimensions of Human Rights. Heidelberg: Springer, 2012, p. 63-80.

HART, Herbert, El concepto de derecho. Buenos Aires: Abeledo Perrot, 1995.

HIERRO, Liborio. Los derechos humanos. Una concepción de la justicia. Madrid: Marcial Pons, 2016.

KELSEN, Hans. ¿Qué es justicia? Barcelona: Planeta- De Agostini, 1993.

MACINTYRE, Alasdair. Animales racionales y dependientes. Por qué los seres humanos necesitamos las virtudes. Barcelona: Paidós, 2001. 
MASSINI, Carlos, La prudencia jurídica. Introducción a la gnoseología del Derecho, Buenos Aires: Abeledo-Perrot, 1984.

NIKKEN, Pedro, La protección internacional de los derechos humanos. Su desarrollo progresivo. Madrid: Civitas, 1987.

NOGUEIRA, Humberto, Teoría y dogmática de los derechos fundamentales. México: Universidad Nacional Autónoma de México, 2003.

PINTO, Mónica. El principio pro homine. Criterios de hermenéutica y pautas para la regulación de los derechos humanos. In ABREGU, Martín, (coord.). La aplicación de los tratados sobre derechos humanos por los tribunales locales. Buenos Aires: Ediciones del Puerto, 1997, p. 163-172.

SILVA, Fernando y SÁMANO, José. Principio pro homine vs restricciones constitucionales: ¿Es posible constitucionalizar el autoritarismo? Revista del Instituto de la Judicatura Federal, n. 37, 2014, p. 235-268.

TASIOULAS, John. La realidad moral de los derechos humanos. Anuario de Derechos humanos, n. 4, p. 41-67, 2011.

TRUJILLO, Isabel y VIOLA, Francesco. What Human Rights are not (or not only). A negative path to human rights practice. Nueva York: Nova Publishers, 2014.

TRUJILLO, Isabel. Derechos y falsos derechos: Derechos razonables y no razonables. Persona y Derecho, n. 52, p. 219-236, 2005.

TUGENDHAT, Ernest. Justicia y Derechos humanos. Barcelona: Publicacions Universitat de Barcelona, 1993.

VILLORO, Luis. Sobre el principio de injusticia: la exclusión. Isegoría. Revista de Filosofía, Moral y Política, n. 22, p. 103-142, 2000. 